\title{
COMPARATIVE STUDIES ON THE EFFECT OF SURFACE PREPARATION ON THE QUALITY OF VARNISH COATINGS
}

\author{
Wojciech SKOTNICKI \\ University of Bielsko-Biala, Bielsko-Biala, Poland, EU, wskotnicki@ath.bielsko.pl
}

https://doi.org/10.37904/metal.2019.880

\begin{abstract}
The paper presents research determining the effect of surface preparation on the quality of varnish coatings obtained by electrophorus. The tests were carried out on steel parts used for the construction of trailers and bodies for trucks. The quality of the paint coatings obtained was determined in the corrosion resistance tests carried out using the Ascott $\mathrm{CC} 1000$ salt cell. The research allowed to determine the durability of the electrophoresis coating depending on the method of preparation of the surface on which they were applied. In order to supplement the tests, the thickness of the varnish coating was measured. The measurements were made by magnetic induction. In addition, roughness measurements were made to determine the effect of surface preparation on the corrosion resistance of the tested coatings. The tests were carried out before applying the coating and for the obtained varnish coat. On the basis of the presented tests, the relationship between the surface preparation method and the corrosion resistance of the tested parts was determined.
\end{abstract}

Keywords: Surface, salt cel, electrophoresis coating, roughness, corrosion resistance

\section{INTRODUCTION}

The corrosion rate is influenced by factors such as humidity, temperature and pollution. Acids, bases and salts cause that water coming from moisture or precipitation becomes an electrolyte conducive to the formation of corrosive cells [1]. The ability to correctly determine the corrosive hazards is one of the most important elements necessary for the proper design of corrosion protection. The description of corrosive environments and the methodology for determining these environments are described in the PN-EN ISO 12944-2 standard. Prevention of corrosion is associated with a number of activities, the most important of which are: design of structures including solutions that are unfavorable to the formation and development of corrosion, selection of appropriate construction materials, selection of the appropriate method of corrosion protection and appropriate materials to ensure protection of the structure including the corrosive environment $[2,3]$. The purpose of protective painting is to protect the metal surface against the influence of corrosive agents, and at the same time to obtain the required aesthetic and decorative effects.

The effectiveness of preventing corrosion phenomena by the paint coating depends on the action of anticorrosive pigments, its tightness and adhesion to the substrate [4]. Often, protective properties are a combination of the above factors. Painting can prevent corrosion by: blocking the cathode reaction, blocking the anode reaction, and introducing high resistance to the current flow in the galvanic pair. Fillers and pigments that are included in paints, to improve their protective properties, usually prevent cathodic and anodic reactions simultaneously $[5,6]$.

Preparation of the surface for painting is the most important and the most difficult element in corrosion protection technology. There may be many impurities on steel, which usually require several operations to be removed. Impurities are: reaction products with the surrounding environment; for steel scale, rust, for aluminum oxides, and for zinc oxides and salts (white rust), production impurities, usually hydrophobic (fats, oils, lubricants, old paint coating), atmospheric pollutants (dust, dust and salts) soluble in water, (usually invisible to the eye) [7]. 
An example of paint coatings with a wide range of industrial applications are cataphoretic coatings. Cataphoresis painting is based on the electrochemical application of special cataphoresis paint to the surfaces of metallic objects. In the tub, in which there is an aqueous solution (about $60-75 \%$ by volume) of resins and pigments (about $15-20 \%$ ) and special additives (about $5-10 \%$ ), painted objects are dipped. Painted objects are a cathode (-), while the positive electrodes are located near the walls of the bathtub. Negatively charged painted objects attract positively charged paint particles. The coating after painting must be rinsed and dried. Cataphoresis painting gives relatively thin, but very even and tight coatings, even on objects with a considerable degree of complexity of shapes. This process allows to reduce the losses of painting material to the level of $3-6 \%$.

\section{OWN RESEARCH}

The tests were carried out on steel parts used for construction of trailers and bodies for trucks (Figure 1). Electrophoretic painting consisted of immersing the cleaned element in a bath with water-thinnable paint Cathoprime QT82-9436 and simultaneous flow of electric current. Cataphoresis painting was carried out in an acid solution $\mathrm{pH} 5.8$ - 6.5. The main regulator of the coating thickness were: the magnitude of the voltage and the time of electrodeposition. The voltage was applied in the range of $230-270 \mathrm{~V}$, and the time was 3 minutes. After painting, the paint coating was dried at $180^{\circ} \mathrm{C}$ for $30 \mathrm{~min}$.
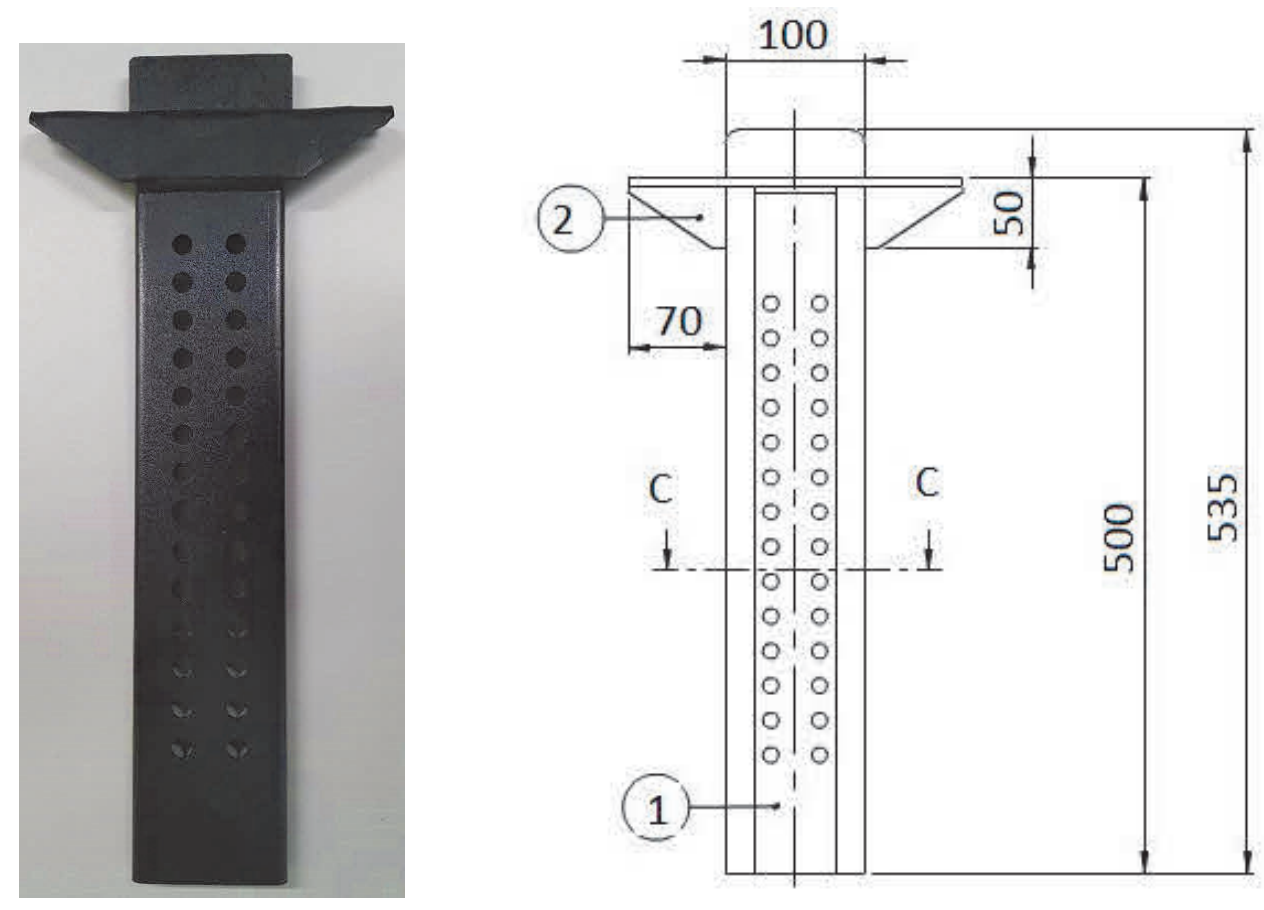

Figure 1 Research object

The test samples were divided into two groups due to the method of surface preparation. The first group (group 1 ) are samples after cold rolling. The second group (group 2) are samples which after rolling were additionally mechanically cleaned - abrasive blast-cleaning. Abrasive blast-cleaning was performed using a pneumatic cleaning cabin with a cylindrical jet made of boron carbide. The angle of inclination of the cleaning nozzle to treated surface was approximately $45^{\circ}$ at an operating pressure of $0.4 \mathrm{MPa}$. Abrasive blast-cleaning was performed using typical A95 corundum with a grain size of 1-2 mm and a hardness of $1355 \mathrm{HV}$.

The presented research included: measurements of the roughness of the obtained coatings and measurements of their thickness. In addition, corrosion resistance tests were carried out in a salt chamber to determine the method of surface preparation for corrosion resistance of cataphoretic coatings. 


\section{TEST RESULTS}

After preparing the part, surface geometry tests were carried out, which can significantly affect the final effect of the quality of the obtained protective coating. Stereometric examinations were carried out in 3D and using the Perthometer Concept (MAHR) profilometer. Sample isometric images of the surface are shown in Figure 2 and Figure 3. The results of roughness measurements for surfaces without a coating and with a protective coating are shown in Figure 4.
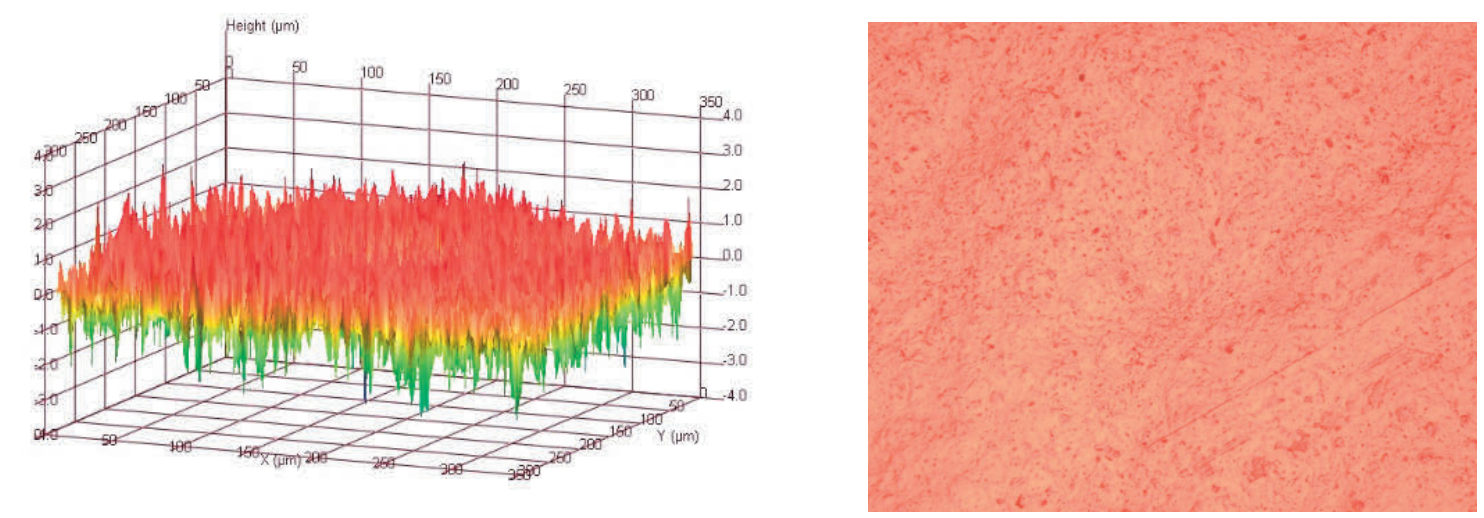

Figure 2 Isometric image of the surface after cold rolling
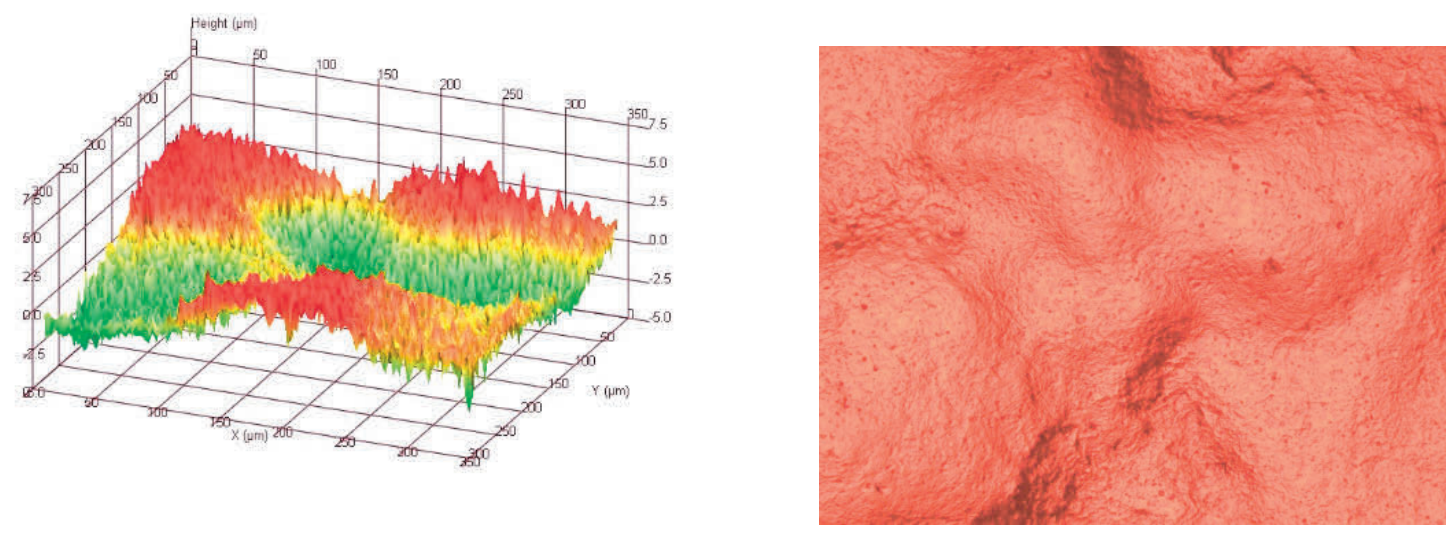

Figure 3 Isometric image of the surface with abrasive blast-cleaning

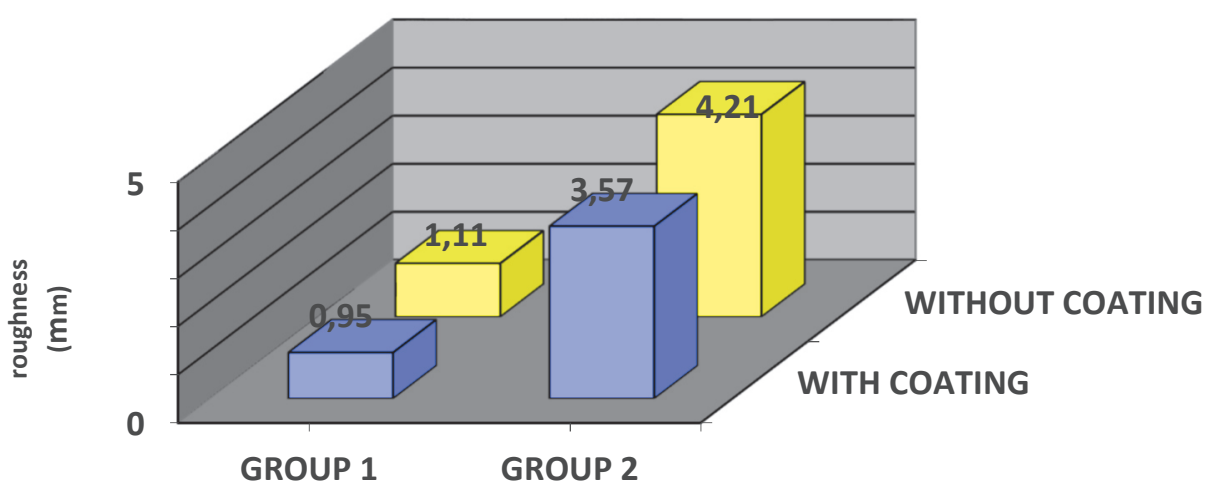

Figure 4 Roughness measurement results - SRa parameter

In addition, the thickness of the coating protecting the steel parts was tested by magnetic induction. The type of surface cleaning can affect the thickness of the paint coat and its uniformity. The method consists in 
measuring the resistance of the magnetic flux passing through the coating and the substrate. The coating thickness meter applied to magnetic and non-magnetic substrates in the version with the probe on the wire was used for the tests. Thanks to the use of electronic gauges measuring the thickness of the varnish coat in a non-destructive manner, the condition of the coating can be determined. Measured elements were previously cleaned to obtain an accurate result, after which a measurement was carried out. For the calibration of the device, standards with known thicknesses in accordance with the type of coating and the substrate were used. For each of the samples, 10 thickness measurements were taken at randomly selected locations. The results are shown in Table 1 and Figure 5.

Table 1 The results of coating thickness measurements

\begin{tabular}{|c|c|c|c|c|c|c|c|c|c|c|c|}
\hline & \multicolumn{8}{|c|}{ The number of the measurement and the thickness of the coating $(\mu \mathrm{m})$} \\
\cline { 2 - 14 } & 1 & 2 & 3 & 4 & 5 & 6 & 7 & 8 & 9 & 10 & Avg \\
\hline Group 1 & $\begin{array}{c}31 \\
\min \end{array}$ & $\begin{array}{c}35 \\
\max \end{array}$ & 33 & 35 & 32 & 31 & 32 & 33 & 35 & 33 & $\mathbf{3 3}$ \\
\hline Group 2 & 19 & 25 & $\begin{array}{c}18 \\
\text { min }\end{array}$ & 33 & 29 & 22 & $\begin{array}{c}38 \\
\max \end{array}$ & 25 & 33 & 26 & $\mathbf{2 6 . 8}$ \\
\hline
\end{tabular}

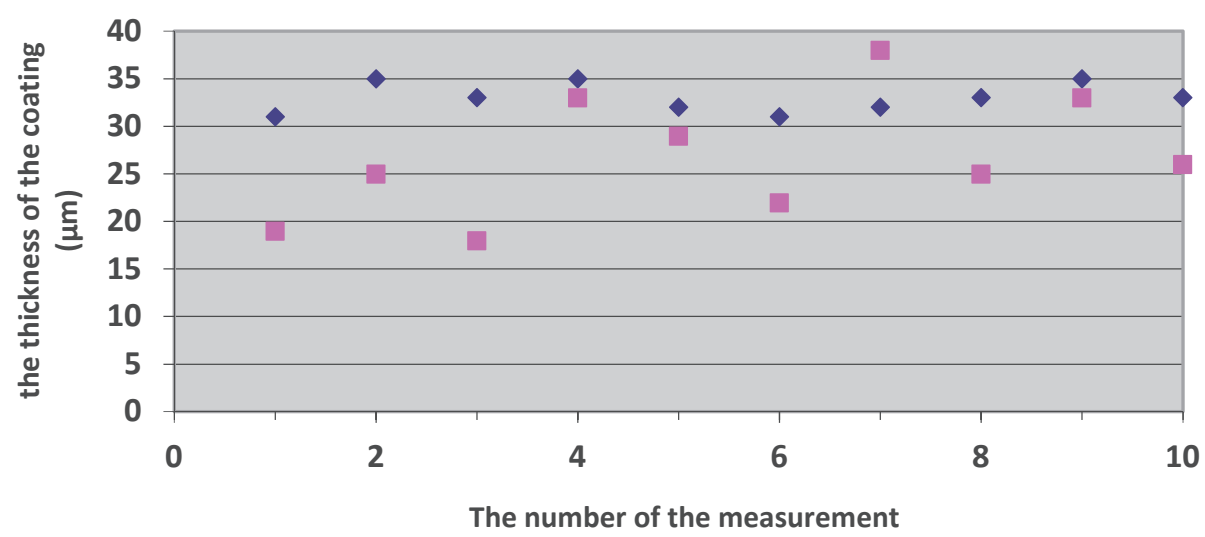

Figure 5 Diagram of coating thickness measurements

Corrosion resistance tests were carried out in a salt chamber (NSS). The tests were carried out in accordance with PN-EN 9227: 2012. The salt chamber used for testing met the conditions for homogeneity and even distribution of the sprayed liquid. The parameters of the accelerated corrosion process were as follows: corrosive medium - $\mathrm{NaCl} 50 \pm 5 \mathrm{~g} / \mathrm{dm}^{3}$, air pressure 1 bar, inside the chamber $35^{\circ} \mathrm{C}$. The construction of the brackets and the chamber itself was selected so that the sprayed salt mist would not fall directly onto the surface of the tested samples. Samples were placed in the chamber at an angle of $30^{\circ}$ to the substrate. The research was carried out until the first signs of the so-called "Red corrosion". For both parts it was 72 hours (Figure 6). In order to verify and supplement the obtained results, the corrosion resistance test was continued until 168 h (Figure 7).
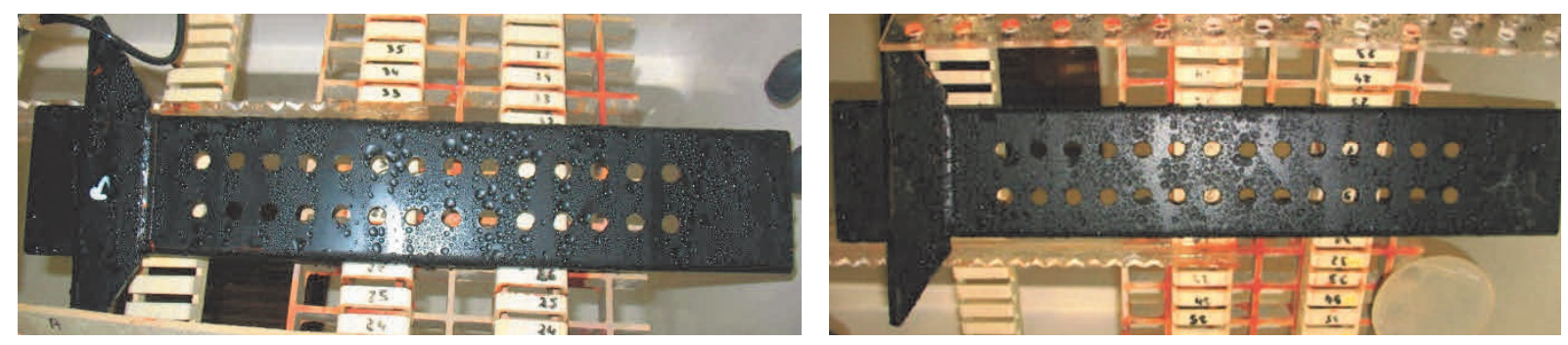

Figure 6 Corrosion tests - view of the tested parts after 72 hours 

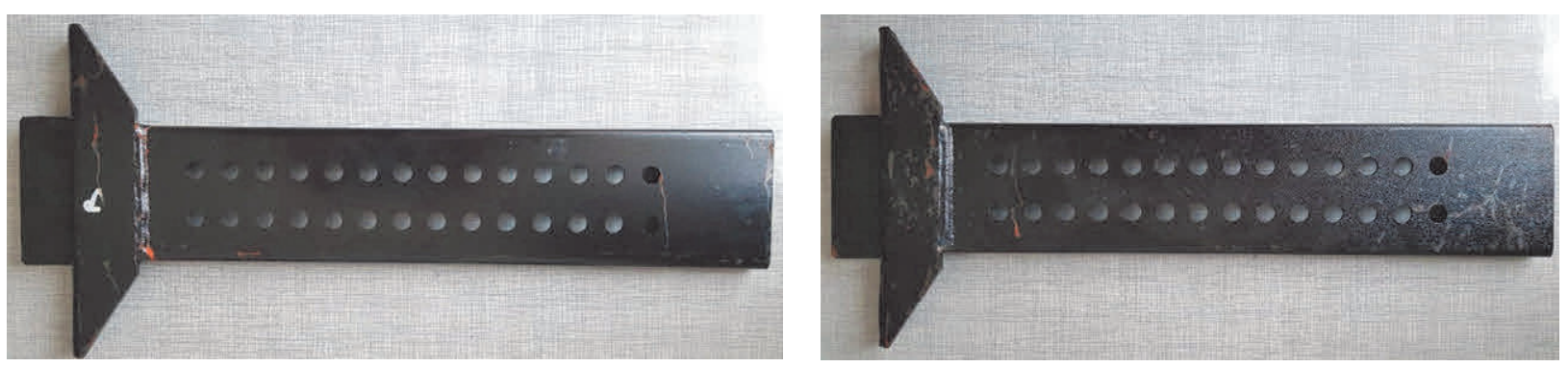

Figure 7 Corrosion tests - view of the tested parts after 168 hours

After removal from the chamber, the samples were purified in $12 \% \mathrm{HCl}$ with the addition of $0.1 \%$ corrosion inhibitor. Next, observations of the surface condition of the coatings were carried out. The samples were assessed with the unaided eye in daylight.

\section{RESULTS ANALYSIS}

Literature data indicate that the surface roughness of coatings may affect their performance. It is believed that too great a roughness may cause a decrease in corrosion resistance and a reduction in mechanical properties. During the research, the influence of the quality of the initial surface on the quality of the obtained varnish coating was noticed. The first stage of the research was to measure the roughness of the paint coatings obtained. The average value of the SRa parameter for the abrasive blast-cleaning surface was $3.57 \mu \mathrm{m}$. In the second case, the arithmetic mean deviation of the profile from the mean line was $0.95 \mu \mathrm{m}$. The differences result from the type of surface treatments carried out. Abrasive blast-cleaning causes a larger surface development.

The thickness of the coating has a significant influence on the corrosion rate and the number of places covered by corrosion. When measuring the thickness of the coating, it was observed that the coating obtained on the surface being abrasive blast-cleaning is characterized by large irregularities. Measured varnish thickness is in the range of $19-38 \mu \mathrm{m}$. The obtained results may indicate a decrease in anti-corrosion as well as operational properties. The rate of wear of the coating is a criterion for atmospheric and mechanical impact. A layer of lacquer of a smaller thickness will show a greater tendency to mechanical damage. Thus, places without a protective coating exposed to corrosion will be created. The coating obtained on the non-machined part was uniform and its thickness was from 31 to $35 \mu \mathrm{m}$.

The last stage of the research was the corrosion resistance tests carried out in the salt chamber. These tests were aimed at confirming and verifying the impact of the previously obtained thickness and roughness results on the resistance of atmospheric factors. In the case of both parts after 72 hours, "Red corrosion" appeared on the surface. Research continued until 168 hours. After this time, the parts were inspected. It should be noted that the abrasive blast-cleaning surface is more exposed to the phenomenon of corrosion. The reason for this phenomenon is to increase the surface area of the rough, which maintains more moisture, and this in turn accelerates the process of corrosion and oxidation. In addition, in the case of large uneven surfaces, uneven tops attach to each other, causing abrasive wear.

\section{SUMMARY AND CONCLUSIONS}

The following conclusions can be drawn on the basis of the research:

- $\quad$ The coating thickness of the parts after cold rolling is more uniform and is in the range of 31-35 $\mu \mathrm{m}$.

- The coating obtained on abrasive blast-cleaning parts is more irregular and the measured thickness value is between 19 and $38 \mu \mathrm{m}$.

- $\quad$ After 72 hours, "red corrosion" appeared in both cases. 
- With the extension of the corrosion test time to 168 hours, the unmarked element showed a greater tendency to corrosion.

- $\quad$ The surface condition of the elements before the application of the protective coating can affect both the thickness of the coating and the corrosion resistance.

\section{REFERENCES}

[1] CLAYDON, D. Performance testing of anticorrosive coatings. Coatings World. Vol. 2. 2003. pp. 26-33.

[2] FERLAUTO, E., EMAMI M., GALANTEFOX, J., GRIVNA, E., HABECK, L. JONES, S., OEBSER, J., PREVOST, G. and VETTER, L. Selection of corrosion test methods based on mechanism principles. Journal of Coatings Technology. 1994. Vol. 66 (835). pp. 85-97.

[3] SKERRY, B. and SIMPSON, CH. Accelerated test method for assessing corrosion and weathering of paints for atmospheric corrosion control. Corrosion. 1993. Vol. 49 (8) pp. 663-674.

[4] BIEGUS, A. Projektowanie konstrukcji stalowych wg. Eurokodu 3. 1st ed. Wrocław: Politechnika Wrocławska, 2010. pp. 5-7.

[5] SUROWSKA, B. Wybrane zagadnienia z korozji i ochrony przed korozją. 1st ed. Lublin: Politechnika Lubelska, 2002. pp. 6-13.

[6] SZŁAPA, I., JĘDRZEJCZYK, D. and SKOTNICKI, W. The assesment of corrosion impact on mechanical properties change of steel fasteners protected by different zinc coating - stage 1. In METAL 2015: 24 ${ }^{\text {th }}$ International Conference on Metallurgy and Materials. Ostrava: TANGER, 2015, pp. 1022-1027.

[7] VINCENT, L. Ask the Coatings Experts: Coating Performance Test Methods for Offshore Service Compared to Actual Service Life. Materials Performance. 2009. Vol. 48 (8). pp. 54-58. 